ISSN: 0213-2079 - ISSN electrónico: 2386-3889

DOI: https://doi.org/10.14201/shhmo2017391169189

\title{
¿LOS LÍMITES DEL HABITUS? MINISTROS REALES EN LA LOMBARDÍA DE CARLOS II*
}

\section{The Limits of Habitus? Royal Ministers in Lombardy during the Reign of Charles II}

\author{
Antonio ÁLVAREZ-OSSORIO ALVARIÑO \\ Universidad Autónoma de Madrid \\ Correo-e: antonio.alvarezossorio@uam.es
}

RESUMEN: Durante el reinado de Carlos II el gobierno político del Estado de Milán experimentó una notable transformación. A lo largo de más de un siglo la carrera ministerial estuvo asociada en torno a una cultura de vida. Los vástagos de las familias patricias de las ciudades lombardas se graduaban en estudios jurídicos, ejercían la abogacía, optaban a puestos bienales y acababan alcanzando las plazas perpetuas en los tribunales supremos. Los lazos de parentesco y la solidaridad colegial influían en el sistema de selección y promoción de los ministros, tanto en los Magistrados Ordinario y Extraordinario, como en el Senado. El ideal de servicio estaba vinculado a unas expectativas de progresión en el cursus honorum togado. Entre los patricios se consideraba que este corso delle lettere era la vía nobiliaria que garantizaba el mando en la sociedad, concebido como una recompensa por los años de estudio y de esfuerzo en el servicio de cargos medianos. Durante la regencia de Mariana de Austria este sistema de carrera ministerial se resquebrajó, cuando en la corte de Madrid se comenzaron a vender plazas ministeriales por parte del consejo de Italia. Bajo Carlos II la venalidad de magistraturas alteró el estilo secular de promoción basado en la nómina

* Este estudio se ha realizado en el marco del proyecto «Sociedad cortesana y redes diplomáticas: la proyección europea de la monarquía de España», ref. HAR2015-67069-P (MINECO-FEDER), financiado por la Dirección General de Investigación del Ministerio de Economía y Competitividad y por el Fondo Europeo de Desarrollo Regional.

(C) Ediciones Universidad de Salamanca / ®@ Stud. his., H. ${ }^{a}$ mod., 39, n. 1 (2017), pp. 169-189 
provincial, favoreciendo la movilidad social en el acceso a la condición de ministro del rey de España y duque de Milán en los tribunales lombardos.

Palabras clave: habitus; ministros regios; Estado de Milán; Carlos II; monarquía de España.

ABSTRACT: During the reign of Charles II the political government of the State of Milan underwent a remarkable change. For more than a century the ministerial career was linked to and based around a way of life. The scions of patriarchal families from the cities of Lombardy graduated in legal studies, practiced as lawyers, had the choice of biennial positions and ended up in lifelong appointments to the supreme courts. Family ties and the old-boys' network influenced the system of selection and promotion for ministers, both among ordinary and extraordinary magistrates as well as in the Senate. The ideal of service was linked to expectations of progression in the judicial cursus honorum. Among patricians the corso delle lettere was considered the path for the nobility which guaranteed control of society and it was seen as recompense for the years of study and effort in mid-level posts. During the regency of Mariana of Austria this system of ministerial career fractured when the Council of Italy began to sell these ministerial positions at the court of Madrid. Under Charles II the venality of the judiciary altered the secular nature of promotion based on the provincial roster, favouring social mobility in the obtention of the position of minister to the King of Spain and Duke of Milan, in the courts of Lombardy.

Key words: habitus; royal officers; Milan State; Charles II; Spanish Monarchy.

\section{El habitus de los ministros Reales en el Estado de Milán}

Durante los reinados de Carlos V y Felipe II se consolidó tanto en la corte regia como en Italia la planta de gobierno de los reinos de Nápoles y de Sicilia, así como del Estado de Milán. Desde mediados del siglo xvi, la configuración del consejo de Italia contribuyó de forma decisiva a estructurar la carrera ministerial en las provincias italianas ${ }^{1}$. La creación del consejo estableció un nuevo

1. Rivero Rodríguez, M.: Felipe II y el Gobierno de Italia. Madrid, 1998, pp. 57-212; y Álvarez-Ossorio Alvariño, A.: «Le origini del Consiglio d'Italia (1554-1556)», Dimensioni e problemi della ricerca storica, 1, 2003, pp. 163-195.

(C) Ediciones Universidad de Salamanca / ®@ Stud. his., H. ${ }^{a}$ mod., 39, n. 1 (2017), pp. 169-189 
hito en el predominio de los letrados en la administración de Italia. A través de las consultas al monarca el consejo logró delimitar un espacio estratégico atribuyéndose en buena medida el ejercicio de las regalías, en parte a costa de la prestancia de los virreyes y gobernadores, aunque en ciertos ámbitos también asumiendo competencias de los tribunales supremos establecidos en los reinos. Durante la segunda mitad del siglo xvi se incrementó la estabilidad de la planta de gobierno en lo relativo a la procedencia nacional de los ministros y oficiales regios en Italia, los criterios de selección y promoción, la formación específica y los grados del cursus honorum.

Según el Diccionario de Autoridades, ministro es «el juez que se emplea en la administración de justicia, decidiendo y sentenciando los pleitos o causas, o en el gobierno, para resolución de otros negocios políticos y económicos, ya sea por sí solo o incluido en algún tribunal, donde vota con los demás»². En el mismo diccionario ministerio significaba «el gobierno de Estado en los negocios importantes de un reino o república» o «el empleo de un ministro».

El sistema del ministerio presentaba rasgos diferenciados en las tres provincias italianas. En el Estado de Milán se consolidó un cursus honorum preciso en la carrera togada. Los hijos de familias pertenecientes a los patriciados de las principales ciudades lombardas como Milán, Pavía, Cremona, Como, Lodi y Alessandria, entre otras, realizaban estudios de derecho y luego se inscribían en el colegio de nobles jurisconsultos de su ciudad natal ${ }^{3}$. Tras ejercer unos años la abogacía, comenzaban a desempeñar las judicaturas bienales en el servicio regio-ducal. De este modo, acumulaban méritos y experiencia que detallaban en sus hojas de servicio, para reforzar sus memoriales para optar a alguno de los puestos superiores.

En este sentido, la nómina provincial se convirtió en un elemento clave en la promoción de los ministros en el Estado de Milán. El tribunal que contaba con una vacante de un puesto fijo remitía una terna al monarca, que el gobernador enviaba a la corte adjuntando su propia terna y sus comentarios sobre la propuesta del tribunal. Ambas instancias llegaban al consejo de Italia, que elevaba una consulta al monarca explicando las características de la plaza vacante y expresando su parecer sobre los candidatos propuestos desde la provincia. Con frecuencia, los regentes que conformaban el consejo añadían una terna consensuada o varias ternas, en

2. Voz «Ministro», en Diccionario de la lengua castellana..., compuesto por la Real Academia Española, tomo IV, Madrid, 1734, p. 572. Otra acepción de la misma palabra: «Se llaman también los alguaciles, corchetes y demás oficiales inferiores que ejecutan los mandatos y autos de un juez».

3. Mozzarelli, C.: «Strutture sociali e formazioni statuali a Milano e Napoli tra ' 500 e '700», Società e storia, 3, 1978, pp. 431-463.

(C) Ediciones Universidad de Salamanca / ®@ Stud. his., H. ${ }^{a}$ mod., 39, n. 1 (2017), pp. 169-189 
caso de votos particulares de algún miembro del consejo. El rey procedía a la designación definitiva al despachar la consulta del consejo de Italia ${ }^{4}$.

La nómina provincial era la piedra angular en la configuración del ministerio en las provincias italianas. La tramitación de la nómina era igual en los reinos de Nápoles y de Sicilia, con la terna de los tribunales, de los virreyes y del consejo de Italia. Detrás de cada terna interactuaban multitud de factores que eran decisivos en la promoción de los candidatos, desde la formación y la experiencia a las relaciones de parentesco y de facción, y los lazos de colegio. En definitiva, era determinante el grado de influencia desplegado tanto sobre el virrey y su entorno como en los regentes del consejo y en la facción dominante en la corte regia, en la que destacaban los validos y secretarios reales.

Una cuestión crucial en las vacantes de puestos ministeriales en el reino de Nápoles y en el Estado de Milán era la naturaleza nacional de la plaza disponible. En torno a un tercio de los cargos ministeriales en los tribunales supremos de Nápoles y Milán estaban reservados a «forasteros», por lo general españoles. El resto se destinaba a los naturales del territorio. En el caso de las plazas para «forasteros» en Milán y Nápoles solían proveerse en colegiales mayores de las universidades castellanas y de San Clemente en Bolonia, cuando eran puestos que debían ocuparse por letrados y, por tanto, no se trataba de plazas de «capa y espada» ${ }^{5}$.

En el Estado de Milán el cursus honorum de los patricios jurisconsultos que comenzaba en la universidad, continuaba en el foro y el ejercicio de cargos bienales, y culminaba en las judicaturas supremas; se denominaba el corso delle lettere o la via della virtu en el servicio regio-ducal. Entre mediados del siglo xvi y la mitad de la siguiente centuria se consolidó el habitus del patricio convertido en ministro togado en una plaza vitalicia, ya fuese las de abogado fiscal, cuestor de los Magistrados Ordinario o Extraordinario, o senador 6 .

Este habitus comenzaba desde la cuna, ya que muchos ministros lombardos eran hijos, sobrinos o nietos de otros ministros. Las implicaciones de la pertenencia a un tribunal supremo se aprendían desde la infancia. En Nápoles y Milán los

4. Álvarez-Ossorio Alvariño, A.: «Españoles y lombardos en el gobierno del Estado de Milán en tiempos de Federico Borromeo», Studia Borromaica, 18, 2004, pp. 275-302; y SignorotTo, G.: Milán español: guerra, instituciones y gobernantes durante el reinado de Felipe $I V$. Madrid, 2006 (ed. original en italiano en 1996).

5. Molas i Ribalta, P.: «Colegiales mayores de Castilla en la Italia española», Studia Histórica. Historia Moderna, 8, 1990, pp. 163-182; y De LARIo, D.: Sobre los orígenes del burócrata moderno. El Colegio de San Clemente de Bolonia durante la impermeabilización habsburguesa (1568-1659). Bolonia, 1983, pp. 159-194.

6. Petronio, U.: «Burocrazia e burocrati nel ducato di Milano dal 1561 al 1706», en AA. VV.: Per Francesco Calasso. Studi degli allievi. Roma, 1978, pp. 481-561.

(C) Ediciones Universidad de Salamanca / ®@ Stud. his., H. ${ }^{a}$ mod., 39, n. 1 (2017), pp. 169-189 
ministros perpetuos eran considerados «semidioses», con una gran capacidad de influencia sobre la vida, hacienda y honra de las familias ${ }^{7}$. La dignidad de ministro debía exteriorizarse en la vida social manteniendo el proporcionado decoro. La residencia, los muebles y pinturas, las vajillas, la forma de vestir, el número y grado de los criados, los coches y la caballeriza eran, entre otros, instrumentos de expresión de una prestancia pública como ministros del rey de España y duque de Milán. Los innumerables retratos de ministros lombardos conservados en la galería de donantes del Ospedale Maggiore en la ciudad de Milán o en colecciones privadas son el espejo de un arquetipo social ${ }^{8}$. El gesto severo de los retratados, la indumentaria togada, el billete en la mano, el despacho y los libros como expresión material de la ciencia jurídica, acreditaban las señas de identidad de un ideal profesional ${ }^{9}$.

La vivienda en la ciudad metrópoli, los barrios y las parroquias donde se casaban y bautizaban a sus hijos, así como las residencias de ocio o villas eran los espacios de un vivir patricio, en los que la buena sociedad urbana anudaba sus lazos de sociabilidad ${ }^{10}$. Este modo de vida patricio compartía unos rasgos comunes con independencia de que sus exponentes se dedicasen a la carrera ministerial, al ejército o a la administración de sus bienes ${ }^{11}$. Los ministros lombardos tenían reservados una posición destacada en las etiquetas de la corte provincial, tanto en eventos extraordinarios como los recibimientos de reinas de España en su paso por Milán, como en el ceremonial ordinario, como la entrada de un nuevo gobernador o las fiestas y comedias en el teatro del palacio regio-ducal ${ }^{12}$.

7. Comparato, V. I.: Uffici e società a Napoli (1600-1647). Florencia, 1974; Bagno, I. del: Legum Doctores. La formazione del ceto giuridico a Napoli tra Cinque e Seicento. Nápoles, 1993; y Rovito, P. L.: Respublica dei togati. Giuristi e società nella Napoli del Seicento. Nápoles, 1982. En el reino de Sicilia los ministros ejercían sus cargos en los tribunales supremos durante dos años, excepto en el tribunal del Patrimonio, donde eran vitalicios. Sciuti Russi, V.: Astrea in Sicilia. II ministero togato nella società siciliana dei secoli XVI e XVII. Nápoles, 1983, pp. 82-112.

8. Véase el catálogo Fiorio, M. T.; Guazzoni, V.; Porzio, F. y Tognoli Bardin, L. (eds.): Ospedale Maggiore/Ca'Granda. Ritratti antichi. Milán, 1986.

9. Buccellati, G., y Marchi, A. (eds.): Bibliotheca Senatus Mediolanensis. I libri giuridici di un Grande Tribunale d'ancien régime. Milán, 2002; y Petronio, U.: «La burocrazia patrizia nel ducato di Milano nell'eta spagnola, 1561-1706», en L'educazione giuridica, t. IV, I, Perugia, 1981, pp. 253-328.

10. Mozzarelli, C.: L'antico regime in villa. Roma, 2004; SPIRITI, A.: «La República de las Parentelas, la genesi del clasicismo lombardo e l'applicazione dello schema-reggia nel secondo Seicento", Arte Lombarda, 141, 2004, pp. 112-121; y D’Amico, S.: Le contrade e la città: Sistema produttivo e spazio urbano a Milano fra Cinque e Seicento. Milán, 1994.

11. Maffi, D.: Il baluardo della corona. Guerra, esercito, finanze e società nella Lombardia seicentesca. Florencia, 2007, pp. 176-208.

12. Cremonini, C.: Alla corte del governatore. Feste, riti e cerimonie a Milano tra XVI e XVIII secolo. Roma, 2012; y Álvarez-Ossorio Alvariño, A.: «La corte de los gobernadores del Estado de Milán», Studi in memoria di Cesare Mozzarelli, 2008, pp. 421-462.

(C) Ediciones Universidad de Salamanca / ®@ Stud. his., H. ${ }^{a}$ mod., 39, n. 1 (2017), pp. 169-189 
El estudio de derecho en las universidades por parte de los jóvenes patricios creaba solidaridades de grupo que podían durar toda la vida. Muestra de ello era la convivencia de estudiantes en colegios como el colegio Borromeo de la universidad de Pavía ${ }^{13}$. Tras obtener sus titulaciones, los patricios togados ingresaban en los colegios de nobles doctores jurisconsultos de cada ciudad, que eran redes a través de las que se expresaba además la pertenencia a la buena sociedad de esa «patria» que era la urbe $e^{14}$.

Tras los años de ejercicio de la abogacía en el foro y el desempeño de los cargos bienales, el éxito de ser incluidos en la nómina provincial les permitía a algunos togados patricios optar a las plazas ministeriales perpetuas. Los puestos más ambicionados eran los cuestoratos del Magistrado Ordinario, el principal tribunal que gestionaba la hacienda del Estado de Milán. Estos cargos servían de plataforma para tratar de obtener uno de los trece asientos del Senado ${ }^{15}$. La cumbre de la carrera ministerial para un jurisconsulto lombardo era el puesto de regente nacional en el consejo de Italia y las presidencias del Magistrado Ordinario y del Senado.

Los principales exponentes del patriciado de las ciudades lombardas se sucedieron durante generaciones en los principales tribunales del Estado ${ }^{16}$. El ministerio estaba en manos de un círculo restringido de familias que combinaban el servicio civil y militar al duque de Milán con la carrera eclesiástica orientada a Roma y a la obtención de beneficios y dignidades episcopales. Unas redes de parentesco que detentaban el poder soberano en tierras lombardas.

El habitus de los ministros patricios implicaba una forma de vestir, una proporcionada exhibición de su estatus en su residencia palaciega y en la villa. El decoro y la distinción se reflejaban en cada momento de su vida social ${ }^{17}$. Entre los reinados de Felipe II y Felipe IV, en torno a la carrera ministerial patricia se fue gestando una cultura del servicio que ensalzaba el liderazgo del grupo dirigente.

13. Zorzoli, M. C.: Università, dottori, giurisconsulti. L'organizzazione della "Facoltà Legale» di Pavia nell'età spagnola. Padua, 1986.

14. Zorzoli, M. C.: «Alcune considerazioni sui collegi dei giuristi nella Lombardia d'antico regime», Annali di Storia moderna e contemporanea, 7, 2001, pp. 449-475. Sobre la idea de «patria» asociada a la «buena sociedad» del patriciado de cada ciudad lombarda, cfr. Politi, G.: Aristocrazia e potere politico nella Cremona di Filippo II. Milán, 1976.

15. Monti, A. M.; «Indicare tamquam deus». I modi della giustizia senatoria nel Ducato di Milano tra Cinque e Seicento. Milán, 2003.

16. Arese, F.: «Le supreme cariche del Ducato di Milano. Da Francesco II Sforza a Filippo V (1531-1706)», Archivio Storico Lombardo, XCVII, 1972, pp. 59-156.

17. Cremonini, C.: Le vie della distinzione. Società, potere e cultura a Milano tra XV e XVIII. Milán, 2012, pp. 49-80.

(C) Ediciones Universidad de Salamanca / 요 Stud. his., H. ${ }^{a}$ mod., 39, n. 1 (2017), pp. 169-189 
El esfuerzo de los estudios universitarios y del ejercicio de la abogacía se veía compensado con la reserva al patriciado de las plazas supremas del ministerio. El poder en la sociedad era el premio por los desvelos en la formación y en el ejercicio de los puestos temporales, como los de podestà en el ámbito local. El corso delle lettere era un camino de la virtù, que conducía a la autoridad y la reputación ${ }^{18}$.

El cursus honorum entendido como strada della nobiltà de los ministros patricios se asociaba a la idea de servicio cívico a la patria y como un derecho de mando. Los ministros pertenecientes a la nobleza urbana lombarda asumieron en parte la imagen del poder de un soberano residente en Madrid. La república del patriciado aseguraba la quietud social en el Estado de Milán. El sistema de promoción ministerial se basaba en la cooptación entre los miembros de los tribunales a través de la nómina, templado por la intervención del gobernador y del consejo de Italia. El regente nacional por parte del Estado de Milán en el consejo de Italia solía ser un patricio lombardo que velaba por sus redes de parentesco, patronazgo y amistad política. La mayor parte de la población lombarda que no formaba parte del selecto círculo del patriciado urbano o de la antigua nobleza estaba excluida del poder ministerial.

\section{2. ¿HABITUS? VISITA Y VENALIDAD, LA NORMALIDAD DE LA VÍA EXTRAORDINARIA}

El poder de los semidioses, de los ministros provinciales perpetuos en la Italia española se veía periódicamente amenazado por la llegada de un comisario o plenipotenciario del soberano, que debía velar por la adecuada administración de justicia ${ }^{19}$. Desde mediados del siglo xvi hasta el reinado de Carlos II las visitas se fueron sucediendo en el Estado de Milán. Como muestra de ello, se enviaron visitadores simultáneamente a Milán, Nápoles y Sicilia en 1559, 1606, 1628 y 1679. La llegada del visitador y sus ayudantes ponía en cuestión las prácticas de los tribunales, apartando a algunos ministros y oficiales del ejercicio de sus plazas y poniendo fin a veces a la carrera de todopoderosos ministros.

El procedimiento extraordinario de la visita favorecía la proliferación de denuncias de los súbditos contra ministros y oficiales. Los visitadores iniciaban

18. Remito a mi estudio La República de las Parentelas: el Estado de Milán en la monarquía de Carlos II. Mantua, 2002.

19. Peytavin, M.: Visite et gouvernement dans le royaume de Naples (XVIe-XVIIe siàcles). Madrid, 2003, pp. 11-191. Sobre las visitas en los tribunales supremos de Castilla remito a GómEZ GONZÁLEZ, I.: «¿Un medio del control extraordinario? Las visitas particulares y secretas a los magistrados de las Chancillerías y audiencias castellanas», en STUMPF, R. y Chaturvedula, N. (eds.): Cargos e oficios nas monarquias ibéricas: provimento, controlo e venalidade (séculos $X V I I-X V I I I)$. Lisboa, 2012, pp. 147-159.

(C) Ediciones Universidad de Salamanca / ®@ Stud. his., H. ${ }^{a}$ mod., 39, n. 1 (2017), pp. 169-189 
causas, buscando pruebas de posibles cargos en los que abundaban casos de corrupción, cohecho, cobro de emolumentos indebidos, vida escandalosa, fraudes al fisco, mala praxis y contravenciones del marco normativo. Senadores y cuestores, cancilleres de la Cancillería Secreta, secretarios del Senado y oficiales de las secretarías de Estado y Guerra del gobernador, y oficiales del sueldo del ejército, entre otros, eran acusados y privados temporalmente de unos puestos vitalicios. A veces los visitadores enfatizaban la humillación pública de los visitados, por ejemplo entrando en casas de los ministros y confiscando su hacienda y muebles, llevándolos en pleno día a un lugar público por las calles de la ciudad, símbolo de la temporal caída en desgracia de su dueño. Frente a los cargos que presentaba el visitador, los ministros y oficiales alegaban la consuetudine, la costumbre y el estilo en la práctica del desempeño de sus plazas ${ }^{20}$. De este modo, los visitados contraponían la praxis de los tribunales frente al marco legal que limitaba su margen de maniobra como ministros.

Con todo, quizá no sea adecuado contraponer la normalidad del sistema ministerial con la irrupción de la vía extraordinaria de la visita. Visitadores y visitados compartían en buena medida los principios de una scientia iuris aplicada al gobierno de la monarquía de España. Los visitadores eran letrados con una formación similar a la de los jurisconsultos colegiales españoles que formaban parte de los tribunales supremos de Milán y Nápoles. Los visitadores podían quebrar trayectorias individuales o familiares, y proponer reformas en los procedimientos de tribunales, ministros y oficiales, pero no cuestionaban un modelo de gobierno en el que imperaban los círculos colegiales de jurisconsultos, ya fuesen españoles o lombardos. Es decir, visitadores y visitados asumían la misma cultura política en cuanto al regimiento de la comunidad, aunque los ministros provinciales denunciasen el perfil ejecutivo y extraordinario de la visita contrapuesto al estilo natural de los tribunales.

Más disruptivo del habitus de los ministros patricios fue el apogeo de la venalidad de plazas supremas en el Estado de Milán. En buena parte del siglo xvir la venta pública de cargos en el Estado de Milán afectaba a oficios menores o medios. El consejo de Italia canalizó estas ventas como un medio para obtener recursos extraordinarios ${ }^{21}$. Durante los reinados de Felipe IV y Carlos II estas ventas alcanzaron niveles significativos. Los pretendientes a estos cargos menores ofrecían un servicio pecuniario, cuyo desembolso les garantizaba la obtención del cargo con diversas cláusulas de goce del mismo.

20. Archivo General de Simancas [en adelante AGS], Secretarías Provinciales, leg. 1951.

21. Archivo Histórico Nacional [en adelante AHN], Estado, leg. 1994.

(C) Ediciones Universidad de Salamanca / ®@ Stud. his., H. ${ }^{a}$ mod., 39, n. 1 (2017), pp. 169-189 
Aunque hubo diversos precedentes en la década de 1640, la venalidad no se extendió a las plazas supremas de Nápoles y Milán hasta los años finales de la regencia de Mariana de Austria ${ }^{22}$. Entre 1673 y 1676 el presidente y los regentes provinciales del consejo de Italia llevaron a cabo el primer gran ciclo de ventas de plazas ministeriales que afectaban a tribunales supremos de los reinos y señoríos de la monarquía de España. En aquella coyuntura se articuló el sistema de la venalidad del ministerio. Este proceso se consolidó y adquirió sus perfiles definitivos durante las dos últimas décadas de la centuria, extendiéndose a las Indias y a España $a^{23}$. Durante la guerra de Sucesión la venalidad se intensificó, continuando bajo el reinado de Felipe $\mathrm{V}$ y en Italia en tiempos del emperador Carlos VI ${ }^{24}$.

Aunque inicialmente el patriciado lombardo participó activamente en la compra de plazas ministeriales, el sistema de la venalidad supuso la quiebra de una forma de servicio y de promoción. El ideal del corso delle lettere concebido como la vía de la virtud fue sustituido por el atajo del oro en un número significativo de plazas de senador y cuestor de los Magistrados Ordinario y Extraordinario durante el reinado de Carlos II. La percepción del cursus honorum y las expectativas de optar a cargos perpetuos tras acumular méritos sirviendo las judicaturas temporales se modificaron de forma drástica. El proceso de selección de los ministros había cambiado. Durante un siglo los jurisconsultos patricios iban progresando desde el foro y los puestos temporales hasta el ministerio. Desde la universidad y la pertenencia a los colegios de nobles jurisconsultos de cada ciudad se tejían relaciones, reforzadas con las redes de parentesco y de patronazgo. Este capital relacional, junto a la enumeración de los servicios prestados en cada puesto, quedaba reflejado en una posición en la terna dentro de la nómina provincial.

La venalidad alteró de forma definitiva el estilo antiguo. El concepto de servicio pecuniario sustituyó al ejercicio continuado durante lustros desempeñando oficios temporales ${ }^{25}$. A veces en vez de desembolsar varios miles de reales de a ocho, el

22. Véase mi artículo «La venta de magistraturas en el reino de Nápoles durante los reinados de Carlos II y Felipe V», Chronica Nova, 33, 2007, pp. 57-94.

23. SAnz TAPIA, A.: ¿Corrupción o necesidad? La venta de cargos de gobierno americanos bajo Carlos II (1674-1700). Madrid, 2009; y Gómez GonzÁLEz, I.: «Sobre venalidad y movilidad social en el seno de los tribunales reales», en Andújar Castillo, F. y Felices de Lafuente, M. del M. (eds.): El poder del dinero: ventas de cargos y honores en el Antiguo Régimen. Madrid, 2011, pp. 210-222.

24. AndúJar, F.: Necesidad y venalidad: España e Indias, 1704-1711. Madrid, 2008.

25. Sobre el concepto del servicio al monarca véase Esteban Estríngana, A. (ed.): Servir al rey en la monarquía de los Austrias. Medios, fines y logros del servicio al soberano en los siglos XVI y XVII. Madrid, 2012; así como la valiosa aportación sobre el habitus de los oficiales reales en el reino de Valencia que plantea GANDOULPHE, P.: «Servir al rey: valores, representaciones y prácticas. El caso de los oficiales reales en Valencia (siglos XVI-XVII)», en PARDo Molero, J.

(C) Ediciones Universidad de Salamanca / ®@ Stud. his., H. ${ }^{a}$ mod., 39, n. 1 (2017), pp. 169-189 
pretendiente ofrecía levantar tropas, lo que en definitiva equivalía a sufragar el coste de la leva y los gastos complementarios. Con todo, la naturaleza del servicio era radicalmente diferente.

También fue variando la vía de venta de plazas ministeriales en Milán y Nápoles. Inicialmente el proceso se canalizó desde el consejo de Italia. En las dos últimas décadas de la centuria, la secretaría del despacho universal fue asumiendo un protagonismo creciente. Este cambio tuvo un impacto relevante en la configuración de la sociedad política lombarda. Mientras la venalidad del ministerio estuvo en manos del consejo de Italia, la participación de los regentes provinciales por parte del Estado de Milán aseguraba el funcionamiento de las redes de poder que vinculaban el patriciado lombardo con la corte de Madrid. Los dos regentes por el Estado de Milán por lo general habían desempeñado el puesto de senador, anudando relaciones con las principales familias patricias. En cambio, la secretaría del despacho universal era un órgano relativamente ajeno a las redes de complicidad con las oligarquías locales. Los agentes de negocios que actuaban en Madrid ofrecían su mediación a los pretendientes de plazas, y buscaban influir en los ámbitos decisivos para conseguir la compra de los puestos ministeriales, ya fuese en el entorno del valido o primer ministro, en el de la reina, en el confesor real o en influyentes miembros de las casas reales.

La venalidad de fiscalías, cuestoratos y plazas senatoriales tenía una dimensión social decisiva. Frente a la endogamia patricia, los grupos sociales emergentes enriquecidos con ocupaciones más o menos viles según las categorías patricias podían por fin optar a ingresar en los tribunales supremos lombardos y convertirse en ministros del rey. Tocaba a su fin el monopolio por parte del patriciado de las plazas reservadas a súbditos del territorio, en torno a dos tercios de las plazas de abogado fiscal, cuestor y senador. Estas familias nuevas compraban al rey títulos de nobleza y feudos, adquiriendo o construyendo palacios que expresasen su ascensión social.

Esta nueva realidad provocó la vigorosa oposición de los tribunales supremos del Estado de Milán, que reivindicaron que se mantuviese el sistema de cooptación a través de la nómina provincial como método de selección de los sujetos «más capaces e idóneos». El Magistrado Ordinario se lamentaba de la pérdida de reputación y autoridad que para el tribunal suponía que «sujetos de todas las esferas» fueran ministros, es decir, que familias nuevas y advenedizos enriquecidos de origen plebeyo y «vil» ostentasen la dignidad de ministros reales ${ }^{26}$.

F. y Lomas Cortés, M. (eds.): Oficiales reales. Los ministros de la monarquía católica, siglos XVI-XVII. Valencia, 2012, pp. 55-75.

26. AHN, Estado, leg. 1994.

(C) Ediciones Universidad de Salamanca / ®@ Stud. his., H. ${ }^{a}$ mod., 39, n. 1 (2017), pp. 169-189 
El patriciado milanés lideró la oposición contra la venalidad de plazas ministeriales, denunciando que suponía el final de la vía de la «virtud y el mérito» ${ }^{27}$. Durante el gobierno de Juan José de Austria la Congregación del Estado, órgano del que formaban parte las ciudades y condados lombardos, atacó el sistema de la venalidad y ensalzó el estilo antiguo, una cultura de vida que permitía acceder al ministerio a través de la prattica delle leggi e del foro. Según la Congregación, las plazas de ministros eran la retribución «natural» de la virtud, y el mecanismo de la nómina provincial garantizaba el mérito e idoneidad en la selección de los ministros.

El patriciado defendió la idoneidad de un babitus que había caracterizado el sistema ministerial en Lombardía durante más de un siglo. La defensa del corso delle lettere fracasó. En tiempos del primer ministro, el duque de Medinaceli, se alcanzó un acuerdo tácito fundado en el mantenimiento de la venalidad de plazas ministeriales, combinado con la continuidad de los procesos de promoción habituales articulados en torno a la nómina provincial para un número relevante de asientos en el Senado y los Magistrados. Esta solución de compromiso se mantuvo en el tiempo, prologándose en la Lombardía bajo el emperador Carlos VI. La venalidad de plazas de senador y cuestor pasó de ser un recurso extraordinario vinculado a una hipotética necessitas de la monarquía a una vía ordinaria de promoción en el servicio al soberano.

\section{CARLOS II Y SUS MINISTROS}

La dinámica del sistema ministerial en el Estado de Milán durante el reinado de Carlos II permite plantear algunas reflexiones sobre la evolución del concepto de servicio, las formas de ejercicio de los puestos, las expectativas de promoción y los mecanismos de selección de los ministros regios.

La forma y función del ministerio experimentaron una notable transformación en tiempos de Carlos II, tanto en los reinos de la monarquía como en el gobierno de corte. La plasmación de estos cambios se materializó en muchos casos a través de formas institucionales ya existentes, pero que adquirieron un alcance cuantitativamente más amplio. Por un lado, en los consejos ubicados en el palacio real proliferaron los ministros de capa y espada, indicio de la consolidación del proceso de «aristocratización» de los consejos, con la entrada de nobles titulados en consejos que tenían una naturaleza esencialmente jurisdiccional. El número de consejeros de capa y espada se incrementó de forma sustancial tanto en el consejo

27. Archivio Storico Civico (Milán), Dicasteri, 161.

(C) Ediciones Universidad de Salamanca / ®@ Stud. his., H. ${ }^{a}$ mod., 39, n. 1 (2017), pp. 169-189 
de Italia como en los consejos de Aragón y de Indias ${ }^{28}$. Las presidencias de los consejos recayeron en buena medida en grandes de España o exponentes de la alta nobleza de sangre.

Parece significativo que un letrado napolitano tan relevante como Francesco Moles porfiase por vestir como un consejero de capa y espada, y se negase a ponerse la toga cuando en abril de 1699 fue nombrado por el rey Juez Conservador del Patrimonio Real, entrando como miembro de capa y espada en el consejo de Italia ${ }^{29}$. En su dilatada carrera ministerial Moles había sido abogado, juez dela Gran Corte de la Vicaria en Nápoles, presidente de la cámara de la Sumaria, visitador general en el Estado de Milán, regente por el reino de Nápoles en el consejo de Italia, Gran Canciller en Milán y regente del Consejo Colateral en Nápoles. Es decir, había servido las principales dignidades reservadas a los letrados en el gobierno de Italia. Su resistencia a vestir la toga pudo deberse a cuestiones de precedencia ceremonial, o a estrategias de carrera y de familia, porque en ese periodo se dedicaba más a ejercer puestos diplomáticos como la embajada en Venecia, o porque desease identificarse con la nobleza de sangre, al haber desposado a su hijo con Maddalena Trivulzio y al obtener en 1689 la agregación al seggio de Portanova. Su negativa rotunda a ponerse la toga y optar por la espada suscitó el escándalo de sus colegas letrados del consejo de Italia, provocando un durísimo enfrentamiento.

En abril de 1699 los regentes del consejo de Italia elevaron una consulta a Carlos II oponiéndose a que Moles entrase con espada en el consejo. Los regentes recordaron al monarca que el napolitano había servido en los principales puestos reservados a letrados, llevando la toga hasta que fue nombrado enviado a Génova, «donde mudó traje, sirviendo con capa y espada», al igual que en la embajada de Venecia. Los regentes defendieron la dignidad de la toga, vestimenta que habían adoptado aquellos letrados que además ostentaban títulos nobiliarios de Castilla o eran hijos de grandes de España. En la consulta se indicaba que «la toga ha honrado toda su vida a Don Francisco Moles» y que negarse a vestirla en el tribunal supremo y empeñarse en vestir con espada constituía un «desprecio» al honor de la magistratura. El consejo de Italia tan solo reconocía dos precedentes de que letrados vistiesen con espada en tribunales de justicia en el palacio real,

28. Schäfer, E.: El Consejo Real y Supremo de las Indias. 2 vols., reedic. Salamanca, 2003 (ed. original en castellano en 1935-1947), vol. I, pp. 260-262 (sobre la proliferación de consejeros de capa bajo Carlos II); Arrieta Alberdi, J.: El Consejo Supremo de la Corona de Aragón (1494-1707). Zaragoza, 1994, pp. 194-197 y 371-376; y GonZÁlez de SAN SEgundo, M. A.: «Los consejeros de capa y espada en el Consejo de Aragón (la nobleza aragonesa en el gobierno de la Monarquía)», en Iglesias, C. (dir.): Nobleza y sociedad. Tomo III, Oviedo, 1999, pp. 145-194.

29. AHN, Estado, leg. 2179.

(C) Ediciones Universidad de Salamanca / ®@ Stud. his., H. ${ }^{a}$ mod., 39, n. 1 (2017), pp. 169-189 
mencionando los casos del conde de Castrillo y del conde de Peñaranda, tras desempeñar este su misión diplomática en Munster. Más allá de los conflictos entre grupos dentro del consejo, la polémica sobre si Moles debía entrar en el consejo de Italia con espada o con toga puso de relieve la tensión entre los magistrados y el ascenso de los consejeros de capa. El servicio en cargos diplomáticos era el pretexto para que los letrados encumbrados por el favor real abandonasen la toga y optasen por llevar espada, al pasar a «puestos políticos», «mudando de estado y profesión ${ }^{30}$. Finalmente Moles fue nombrado embajador del rey católico ante el emperador Leopoldo I, siendo una figura crucial en los asuntos de Italia durante la guerra de Sucesión ${ }^{31}$.

Como se ha indicado, durante la regencia de Mariana de Austria se implantó a gran escala el proceso de venalidad de plazas ministeriales y magistraturas en los territorios italianos, dinámica que se extendió a las Indias y a los reinos españoles a lo largo del reinado de Carlos II. La venalidad se encauzó a través de unas determinadas figuras, las plazas supernumerarias y de futura sucesión, que alteraban las formas de servicios entre el rey y sus ministros. Los tribunales supremos de Italia tenían un número estable de plazas supremas. Por ejemplo, en Milán el Senado estaba compuesto por trece senadores, y cada Magistrado contaba con seis cuestores. Al no haber vacantes de plazas de número, se optó por vender en Madrid puestos supernumerarios. En el nombramiento regio de cada plaza ministerial beneficiada se especificaban los derechos inherentes a la compra, como las condiciones de goce de salarios y emolumentos o el derecho a voto en el tribunal. De este modo, se creó una tipología variable en las formas de servir y desempeñar el ministerio. Este sistema se extendió a los consejos de la corte cuando se vendieron plazas de consejeros.

Asimismo, las sucesivas «reformas» de los consejos y tribunales supremos de los reinos se fundaban en un arquetipo de buen gobierno y de la «planta» ideal para el gobierno de la monarquía. Las «reformas» de tribunales, como la de 1691, suponían reducir sus plazas a un número fijo de una supuesta planta por lo general asociada con el reinado de Felipe $\mathrm{II}^{32}$. Los ministros y oficiales reales «reformados» quedaban excluidos del ejercicio de sus puestos y con frecuencia del goce de salarios y emolumentos. La figura del ministro «reformado» se convirtió en

30. Consulta del consejo de Italia dirigida a Carlos II. Madrid, 22 de abril de 1699. AHN, Estado, leg. 1997.

31. Sobre la trayectoria de Moles durante la guerra remito a Quirós Rosado, R.: «Constantia et fortitudine». La corte de Carlos III y el gobierno de Italia, 1706-1714. Tesis doctoral, Universidad Autónoma de Madrid, 2015.

32. AHN, Estado, leg. 2052.

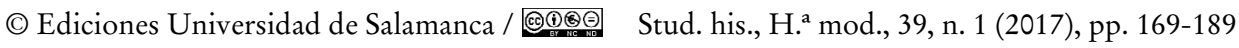


habitual durante el reinado de Carlos II. Estos ministros y oficiales privados de ejercicio y goce elevaban numerosos memoriales al rey solicitando su reingreso o compensaciones económicas para mantener a sus familias. Los ministros y oficiales supernumerarios eran el blanco de estas reformas de tribunales, justificadas por las penurias hacendísticas.

La presión de los ministros y oficiales que tenían una futura sucesión a plazas de número en los tribunales planteaba el debate sobre el carácter perpetuo del ejercicio de los puestos ministeriales en los tribunales supremos. ¿Podían jubilarse los ministros? Los informes que llegaban al consejo de Italia daban cuenta de cómo algunos senadores y cuestores ancianos continuaban sirviendo sus plazas con notables deficiencias de salud que imposibilitaban un adecuado ejercicio de sus responsabilidades ${ }^{33}$. Estos mismos achaques se alegaban por el consejo de Italia al valorar una terna provincial en caso de promoción, alterando el orden de los propuestos por un tribunal o el gobernador. Sin embargo, solo en situaciones relativamente excepcionales se optaba por jubilar a un ministro ${ }^{34}$. En algunos casos el ministro solicitaba la jubilación y pedía mercedes regias como recompensa por la larga trayectoria de servicios. En otros, la jubilación era impuesta y daba la impresión de ser el resultado de pugnas e intereses faccionales más que tratarse de un criterio homogéneo de aplicación general.

En determinadas coyunturas el primer ministro intentó hacer cambios sustanciales en los mecanismos de selección y provisión de puestos estratégicos en el servicio al rey. Juan José de Austria trató de imponer que las secretarias de las embajadas y de los virreyes dejasen de estar dentro de la órbita aristocrática. Por lo general, cada nuevo virrey y embajador proponía a un secretario de su confianza, que en muchos casos pertenecía al personal de servicio de su casa. Bajo el gobierno de Juan José de Austria se intentó que estos secretarios no dependiesen del favor de los nobles que desempeñaban los puestos de virrey o embajador, sino que fueran nombrados por el rey a propuesta de los consejos.

Este intento de cambio crucial en las secretarías vino motivado por una propuesta de Manuel Francisco de Lira, representante diplomático del rey católico ante las Provincias Unidas ${ }^{35}$. En agosto de 1677 Lira se lamentó en carta

33. AGS, Secretarías Provinciales, leg. 1946.

34. Por ejemplo, en el caso del Gran Canciller Diego Salazar en 1616 (AHN, Estado, leg. 1965) o el regente provincial por el Estado de Milán en el consejo de Italia, el marqués Carlo Gallaratti en 1672 (AHN, Estado, leg. 1915).

35. Carrió-Invernizzi, D.: «Manuel de Lira, Spanish Ambassador to The Hague (16711678). The home of the ambassador and his role as agent of artists and art collectors», en CARrió-Invernizzi, D. (dir.): Embajadores culturales. Transferencias y lealtades de la diplomacia española de la Edad Moderna. Madrid, 2016, pp. 205-235.

(C) Ediciones Universidad de Salamanca / ®@ Stud. his., H. ${ }^{a}$ mod., 39, n. 1 (2017), pp. 169-189 
dirigida al monarca desde La Haya del «grave inconveniente que de seis años a esta parte he reparado con perjuicio grave del real servicio de Vuestra Majestad en las mudanzas que he visto de algunas embajadas y otros empleos políticos, y aun militares, donde los que salen de ellos han estilado el llevar consigo los papeles, despachos, minutas y demás instrumentos que debieran dejar para la dirección, inteligencia y gobierno de sus sucesores, de cuyo desacierto resulta el entrarse sin luz en los negocios, o mendigar de otros los informes que les podían dar los instrumentos clásicos de los papeles de la embajada, o puesto donde entran casi a ciegas». Por ello, Lira instaba al soberano que diese una orden general «a todos los que servimos fuera para que dejemos los papeles de nuestros cargos a los que nos sustituyeren ${ }^{36}$.

Al elevar una consulta sobre esta carta al rey, el consejo de Estado consideró acertado velar para que los papeles quedasen archivados en cada negociación. Sin embargo, la respuesta del soberano sobre este tema abrió una nueva dimensión que implicaba la reforma de la estructura de funcionamiento de las embajadas, virreinatos y capitanías generales de la monarquía de España. Carlos II ordenó al consejo de Estado que «por lo que puede conducir a este mismo fin y a mi mayor servicio verá el consejo si será bien que se señalen por nombramiento mío los que hubieren de ser secretarios de los virreyes, gobernadores, capitanes generales y demás ministros de fuera, como se estila en Flandes». De este modo, Juan José de Austria puso de relieve su dilatada experiencia en el gobierno político de la monarquía, ya fuese en Nápoles, Cataluña o los Países Bajos reales. Al ejercer los puestos de virrey y gobernador, así como el mando supremo de los ejércitos en Italia, Cataluña, Flandes y Portugal, don Juan era consciente del papel crucial de los secretarios en el desempeño de tales cargos. El primer ministro optó por «el estilo de Flandes», donde la secretaría de Estado y Guerra era permanente, nombrada por el rey ${ }^{37}$. Un sistema muy diferente del resto de las secretarías de virreyes, gobernadores, embajadores y capitanes generales, en las que los aristócratas elegían a los secretarios entre su personal de confianza.

En septiembre de 1677 el consejo de Estado se opuso abiertamente a la posibilidad de que los virreyes y embajadores pudiesen perder una prerrogativa clave

36. Carta de Manuel Francisco de Lira dirigida a Carlos II. La Haya, 17 de agosto de 1677. AGS, Estado, leg. 4128.

37. LefÈVRe J.: La Secrétairerie d'État et de Guerre sous le régime espagnol (1594-1711). Bruselas, 1934; y VERSELE, J.: «Les secrétaires particuliers des gouverneurs généraux des PaysBas sous Philippe II: aux origines de la Secrétairerie d'État et de Guerre?», en Vermeir, R.; Ebben, M. y Fagel, R. (dirs.): Agentes e identidades en movimiento. España y los Países Bajos, siglos XVI-XVIII. Madrid, 2011, pp. 25-48. 
en sus puestos. El consejo consideraba que los virreyes y embajadores debían seguir eligiendo a secretarios «de toda satisfacción y confianza para el manejo de los empleos que les fían, y que la experiencia ha mostrado que en Flandes el principal manejo le tienen los secretarios de los gobernadores, y no el que está nombrado por Vuestra Majestad para secretario de Estado y Guerra, con que para el punto general no se considera necesario innovar de lo que hasta aquí se ha observado». Esta resistencia a una innovación política de amplio calado puso de relieve la naturaleza del consejo de Estado, que durante el siglo xviI fue una plataforma esencial que garantizaba el control por parte de la aristocracia del gobierno de la monarquía. En aquella sesión votaron en el consejo grandes de España como el marqués de Astorga, el duque de Osuna y el duque de Medinaceli. El marqués de Astorga había sido virrey en Nápoles, y el duque de Osuna había servido mandos militares, el virreinato de Cataluña y el gobierno del Estado de Milán. Ambos grandes conocían la relevancia de la secretaría de estado y guerra, que era el eje de gobierno virreinal en los territorios de la monarquía de España. $\mathrm{Su}$ abierta oposición a estas innovaciones era respaldada por el duque de Medinaceli, que gozaba de la plena confianza de Carlos II y aspiraba fundadamente al valimiento.

Aunque alcanzase el poder con el respaldo de los grandes de España, Juan José de Austria no era una marioneta en manos de la aristocracia de sangre. El primer ministro tenía amplia experiencia y planteamientos claros en su programa de reforma del gobierno de la monarquía. Por ello, la respuesta del monarca al consejo fue larga y detallada, reivindicando la gestión de don Juan en Flandes.

El estilo que el consejo refiere se ha introducido en Flandes en el ejercicio de la secretaría de Estado y Guerra es un abuso que obliga tanto más a que se ponga el remedio conveniente para que aquello corra como debe, y como corrió en el tiempo que gobernaron los Países Bajos el infante don Fernando, y el archiduque Leopoldo, mis tíos, y Don Juan, mi hermano, y así se darán para esto órdenes precisas sin permitir que se falte a ellas con pretexto alguno, y conviniendo que la misma planta se observen todas las demás partes para que en esta se guarda la regularidad que es justo, y se habiliten sujetos de quienes se compongan las secretarías de la corte, resuelvo que conservándose por ahora los secretarios que tienen los virreyes, gobernadores, capitanes generales y embajadores, en lo de adelante se provean las secretarías principales de estos puestos por consulta del consejo a quien tocare, y nombramiento mío, para que las sirvan con el mismo sueldo que les está señalado mientras no se les diere otros empleos, y así se ejecutará, previniendo de ello a los que se nombraron para los cargos referidos al tiempo de elegirlos, dejando a su

(C) Ediciones Universidad de Salamanca / ®@ Stud. his., H. ${ }^{a}$ mod., 39, n. 1 (2017), pp. 169-189 
arbitrio el valerse de las personas que les pareciere para las secretarías de Cámara y de Justicia donde las hubiere ${ }^{38}$.

Con esta orden regia se imponía a todos los virreinatos y gobiernos de la monarquía, así como a las embajadas, el modelo de la secretaría de Estado y Guerra de Flandes. Es decir, un ministro que no estuviese controlado domésticamente por los aristócratas que servían el virreinato o la embajada. Tan solo se dejaba a discreción de los virreyes la designación de una secretaría menor en el gobierno de los reinos, la de cámara y justicia, mientras que la secretaría de Estado y Guerra, que era el núcleo del despacho y ejecución de las órdenes virreinales, pasaba a ser provista a propuesta de los consejos territoriales.

En diciembre de 1678 Juan José de Austria trató de concretar un aspecto esencial de la reforma de las secretarías virreinales y de embajadas, como era si la duración del desempeño de los nuevos secretarios debía ser trienal como los gobiernos virreinales, «o si han de continuar en ella con los sucesores» ${ }^{39}$. Esta disyuntiva puso de manifiesto los titubeos de Juan José de Austria a la hora de imponer el modelo de la secretaría de Estado y Guerra de Flandes, que era dirigida por un ministro permanente y no provisional. El consejo de Estado se opuso rotundamente a que los secretarios principales de los virreinatos y las embajadas fuesen «perpetuos en estas ocupaciones, porque serían más atendidos que los virreyes, gobernadores o embajadores», recomendando "que se les mantenga el tiempo que estuvieren los virreyes». Los grandes de España y los títulos que conformaban el consejo de Estado temían con razón que la pluma eclipsase a la espada, de modo que unos secretarios de Estado y Guerra permanentes acabarían detentando el despacho de los negocios a costa de virreyes y embajadores, cargos de carácter temporal. El rey se conformó con el parecer del consejo de Estado.

Algunos consejos territoriales, como el de Aragón, apoyaron con rotundidad esta medida, que en la práctica debilitaba la figura del virrey al introducir un instrumento de control en el eje del gobierno político de los reinos de la monarquía. En octubre de 1677 el consejo de Aragón estimaba que la aplicación de la medida era «muy conveniente» en la corona de Aragón y que el consejo podía proponer «personas que vayan con noticias de las provincias para la buena dirección de los negocios» ${ }^{40}$. Los consejos compuestos mayoritariamente por togados,

38. Respuesta de Carlos II a la consulta del consejo de Estado, fechada esta en Madrid a 20 de septiembre de 1677. AGS, Estado, leg. 4128.

39. Decreto de Carlos II dirigido al consejo de Estado. Madrid, 7 de diciembre de 1678. AGS, Estado, leg. 2703.

40. Consulta del consejo de Aragón dirigida a Carlos II. Madrid, 3 de noviembre de 1677. AGS, Estado, leg. 2703. 
como el de Aragón, trataban de asegurarse un medio de fiscalización de la labor de los virreyes. Sin embargo, esta reforma radical del despacho de los negocios en virreinatos y embajadas no llegó a consolidarse tras la muerte de don Juan en 1679, como ocurrió con otros intentos de cambio del gobierno de la monarquía propiciados durante su ministerio. $\mathrm{Al}$ afectar a un aspecto crucial en la dinámica política del gobierno de los virreinatos y embajadas este intento acabó fracasando dada la oposición de la aristocracia que manejaba el poder en la corte.

En tiempos de Carlos II también fue significativa la metamorfosis de la figura del valido. Durante los reinados de Felipe III y Felipe IV varios exponentes de la alta aristocracia castellana, como los duques de Lerma y de Uceda, y el condeduque de Olivares, habían dirigido el gobierno de la monarquía y canalizado las mercedes del patronazgo regio. Los validos habían eclipsado el poder de la pluma, convirtiendo a los secretarios reales en meros instrumentos del mando aristocrático de la monarquía. Tras la muerte de don Luis de Haro el sistema del valimiento experimentó una grave crisis. Desde 1661 surgió la disyuntiva de apoyar al rey en el gobierno a través de una junta de ministros o con el respaldo de un «ministro principal» que, a diferencia del valido, tenía una capacidad limitada compartiendo cotas de influencia con los consejos y con los pujantes secretarios del despacho. El 21 de febrero de 1680 el duque de Medinaceli, Juan Francisco de la Cerda, fue nombrado «primer ministro» por Carlos II. Según el diccionario de Autoridades, primer ministro era el «ministro superior que el rey suele nombrar para que le alivie en parte del trabajo del despacho, cometiéndole ciertos negocios con jurisdicción de despacharlos por sí solo» ${ }^{41}$. Bajo Carlos II se configuró la figura del «primer ministro», que implicaba dotar de un carácter «ministerial» al grande de España que gozaba del favor regio.

Ministros supernumerarios, ministros reformados, ministros que compraban sus plazas de magistrados. ¿Cómo afectaba la mutación del sistema ministerial en tiempos de Carlos II a la fidelidad de sus servidores? ¿Cuál era la relación entre venalidad del ministerio y lealtad en los albores de la guerra de Sucesión? El conflicto bélico implicó una intensificación de la venalidad en Italia, que en el reino de Sicilia alcanzó dimensiones inéditas bajo la dominación de Felipe $\mathrm{V}^{42}$. Los ministros y oficiales que habían adquirido sus cargos mediante un servicio pecuniario en Sicilia acreditaron su fidelidad a su soberano hasta la pacífica entrega

41. Diccionario..., op. cit., vol. IV, p. 573.

42. Remito a mi artículo «¿El final de la Sicilia española? Fidelidad, familia y venalidad bajo el virrey marqués de Los Balbases (1707-1713)», en Álvarez-Ossorio, A.; GARcía, B. y León, V. (eds.): La pérdida de Europa. La guerra de Sucesión por la monarquía de España. Madrid, 2007, pp. 831-912. 
ANTONIO ÁLVAREZ-OSSORIO ALVARIÑO

¿LOS LÍMITES DEL HABITUS? MINISTROS REALES EN LA LOMBARDÍA DE CARLOS II

de la isla al duque de Saboya. Venalidad y lealtad confluyeron en el gobierno de Sicilia bajo Felipe V.

\section{Bibliografía}

Álvarezz-Ossorio Alvariño, A.: «¿El final de la Sicilia española? Fidelidad, familia y venalidad bajo el virrey marqués de Los Balbases (1707-1713)», en Álvarez-OssoRIO, A.; GARCíA, B. y León, V. (eds.): La pérdida de Europa. La guerra de Sucesión por la monarquia de España. Madrid, 2007, pp. 831-912.

Álvarez-Ossorio Alvariño, A.: «Españoles y lombardos en el gobierno del Estado de Milán en tiempos de Federico Borromeo», Studia Borromaica, 18, 2004, pp. 275-302.

Álvarez-Ossorio Alvariño, A.: «La corte de los gobernadores del Estado de Milán», Studi in memoria di Cesare Mozzarelli, 2008, pp. 421-462.

Álvarez-Ossorio Alvariño, A.: «La venta de magistraturas en el reino de Nápoles durante los reinados de Carlos II y Felipe V», Chronica nova, 33, 2007, pp. 57-94.

Álvarez-Ossorio Alvariño, A.: «Le origini del Consiglio d'Italia (1554-1556)», Dimensioni e problemi della ricerca storica, 1, 2003, pp. 163-195.

AndúJAR, F.: Necesidad y venalidad: España e Indias, 1704-1711. Madrid, 2008.

Arese, F.: «Le supreme cariche del Ducato di Milano. Da Francesco II Sforza a Filippo V (1531-1706)», Archivio Storico Lombardo, XCVII, 1972, pp. 59-156.

Arrieta Alberdi, J.: El Consejo Supremo de la Corona de Aragón (1494-1707). Zaragoza, 1994.

Bagno, I. del: Legum Doctores. La formazione del ceto giuridico a Napoli tra Cinque e Seicento. Nápoles, 1993.

Buccellati, G., y Marchi, A. (eds.): Bibliotheca Senatus Mediolanensis. I libri giuridici di un Grande Tribunale d'ancien régime. Milán, 2002.

CARrió-Invernizzi, D.: «Manuel de Lira, Spanish Ambassador to The Hague (1671-1678). The Home of the Ambassador and his Role as Agent of Artists and Art Collectors», en CARrió-Invernizzi, D. (dir.): Embajadores culturales. Transferencias y lealtades de la diplomacia española de la Edad Moderna. Madrid, 2016, pp. 205-235.

Comparato, V. I.: Uffici e società a Napoli (1600-1647). Florencia, 1974.

CREMONINI, C.: Alla corte del governatore. Feste, riti e cerimonie a Milano tra XVI e XVIII secolo. Roma, 2012.

Cremonini, C.: Le vie della distinzione. Società, potere e cultura a Milano tra XV e XVIII. Milán, 2012.

D’Amico, S.: Le contrade e la città: Sistema produttivo e spazio urbano a Milano fra Cinque e Seicento. Milán, 1994.

De LARIO, D.: Sobre los orígenes del burócrata moderno. El Colegio de San Clemente de Bolonia durante la impermeabilización habsburguesa (1568-1659). Bolonia, 1983, pp. 159-194.

Esteban Estríngana, A. (ed.): Servir al rey en la monarquía de los Austrias. Medios, fines $y$ logros del servicio al soberano en los siglos XVI y XVII. Madrid, 2012.

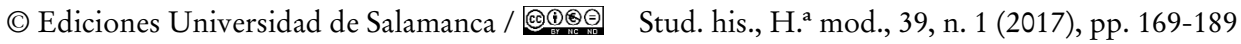


Fiorio, M. T.; Guazzoni, V.; Porzio, F. y Tognoli Bardin, L. (eds.): Ospedale Maggiore/ Ca' Granda. Ritratti antichi. Milán, 1986.

Gandoulphe, P.: «Servir al rey: valores, representaciones y prácticas. El caso de los oficiales reales en Valencia (siglos XVI-XVII)», en Pardo Molero, J. F. y Lomas Cortés, M. (eds.): Oficiales reales. Los ministros de la monarquía católica, siglos XVI-XVII. Valencia, 2012, pp. 55-75.

Gómez GonzÁlez, I.: «¿Un medio del control extraordinario? Las visitas particulares y secretas a los magistrados de las Chancillerías y audiencias castellanas» en STUmPF, R. y Chaturvedula, N. (eds.): Cargos e oficios nas monarquias ibéricas: provimento, controlo e venalidade (séculos XVII-XVIII). Lisboa, 2012, pp. 147-159.

Gómez GONZÁlez, I.: «Sobre venalidad y movilidad social en el seno de los tribunales reales», en Andújar Castillo, F. y Felices de Lafuente, M. del M. (eds.): El poder del dinero: ventas de cargos y honores en el Antiguo Régimen. Madrid, 2011, pp. 210-222.

González de San Segundo, M. A.: «Los consejeros de capa y espada en el Consejo de Aragón (la nobleza aragonesa en el gobierno de la Monarquía)», en Iglesias, C. (dir.): Nobleza y sociedad, tomo III. Oviedo, 1999, pp. 145-194.

LefÈvre J.: La Secrétairerie d'État et de Guerre sous le régime espagnol (1594-1711). Bruselas, 1934.

Mafri, D.: Il baluardo della corona. Guerra, esercito, finanze e società nella Lombardia seicentesca. Florencia, 2007, pp. 176-208.

«Ministro", en Diccionario de la lengua castellana..., compuesto por la Real Academia Española, tomo IV. Madrid, 1734, p. 572.

Molas i Ribalta, P.: «Colegiales mayores de Castilla en la Italia española», Studia Histórica. Historia Moderna, 8, 1990, pp. 163-182.

Monti, A. M.; «Iudicare tamquam deus». I modi della giustizia senatoria nel Ducato di Milano tra Cinque e Seicento. Milán, 2003.

Mozzarelli, C.: L'antico regime in villa, Roma, 2004.

Mozzarelli, C.: «Strutture sociali e formazioni statuali a Milano e Napoli tra '500 e '700», Società e storia, 3, 1978, pp. 431-463.

Petronio, U.: «Burocrazia e burocrati nel ducato di Milano dal 1561 al 1706», en AA. VV.: Per Francesco Calasso. Studi degli allievi. Roma, 1978, pp. 481-561.

Petronio, U.: «La burocrazia patrizia nel ducato di Milano nell'eta spagnola, 1561-1706», en L'educazione giuridica, t. IV, I. Perugia, 1981, pp. 253-328.

Peytavin, M.: Visite et gouvernement dans le royaume de Naples (XVIe-XVIIe siàcles). Madrid, 2003.

Politi, G.: Aristocrazia e potere politico nella Cremona di Filippo II. Milán, 1976.

Quirós Rosado, R.: "Constantia et fortitudine». La corte de Carlos III y el gobierno de Italia, 1706-1714. Tesis doctoral, Universidad Autónoma de Madrid, 2015.

Rivero Rodríguez, M.: Felipe II y el Gobierno de Italia. Madrid, 1998.

Rovito, P. L.: Respublica dei togati. Giuristi e società nella Napoli del Seicento. Nápoles, 1982.

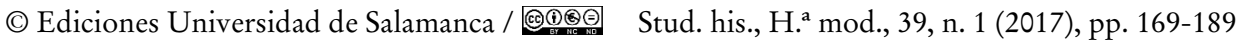


SAnz TAPIA, A.: ¿Corrupción o necesidad? La venta de cargos de gobierno americanos bajo Carlos II (1674-1700). Madrid, 2009.

Schäfer, E.: El Consejo Real y Supremo de las Indias. 2 vols., reedic. Salamanca, 2003 (ed. original en castellano en 1935-1947), vol. I.

ScIUTI Russi, V.: Astrea in Sicilia. II ministero togato nella società siciliana dei secoli XVI e XVII. Nápoles, 1983.

SignorotTo, G.: Milán español: guerra, instituciones y gobernantes durante el reinado de Felipe IV. Madrid, 2006 (ed. original en italiano en 1996).

Spiriti, A.: "La República de las Parentelas, la genesi del clasicismo lombardo e l'applicazione dello schema-reggia nel secondo Seicento», Arte Lombarda, 141, 2004, pp. 112-121.

Versele, J.: «Les secrétaires particuliers des gouverneurs généraux des Pays-Bas sous Philippe II: aux origines de la Secrétairerie d'État et de Guerre?», en Vermeir, R.; Ebben, M. y Fagel, R. (dirs.): Agentes e identidades en movimiento. España y los Países Bajos, siglos XVI-XVIII. Madrid, 2011, pp. 25-48.

Zorzoli, M. C.: «Alcune considerazioni sui collegi dei giuristi nella Lombardia d'antico regime», Annali di Storia moderna e contemporanea, 7, 2001, pp. 449-475.

Zorzoli, M. C.: Università, dottori, giurisconsulti. L'organizzazione della "Facoltà Legale» di Pavia nell'età spagnola. Padua, 1986. 
